\title{
A (não) cobertura dos riscos ambientais: debate sobre silenciamentos do jornalismo
}

\section{The (non) coverage of environmental risks: debate on journalistic silences}

\author{
Eloisa Beling Loose \\ Doutora em Meio Ambiente e Desenvolvimento pela Universidade Federal do Paraná (UFPR), professora do curso de Jornalismo \\ do Centro Universitário Internacional (Uninter). Grupo de Pesquisa Jornalismo Ambiental (CNPq/UFRGS). \\ <eloisa.beling@gmail.com>
}

\section{Ângela Camana}

Doutoranda em Sociologia na Universidade Federal do Rio Grande do Sul (UFRGS). É membro dos grupos de pesquisa TEMAS Tecnologia, Meio Ambiente e Sociedade e do Grupo de Pesquisa Jornalismo Ambiental (CNPq/UFRGS)..

<angela.camana@hotmail.com>

\section{Roberto Villar Belmonte}

Doutorando do Programa de Pós-Graduação em Comunicação e Informação da Universidade Federal do Rio Grande do Sul, professor de jornalismo ambiental no Centro Universitário Ritter dos Reis - UniRitter. Integrante do Grupo de Pesquisa Jornalismo Ambiental (CNPq/UFRGS).

$<$ rvillar21@gmail.com>

\section{RESUMO}

Este artigo propõe um debate sobre o papel do jornalismo no que tange dar visibilidade aos riscos ambientais, ainda que se saiba das dificuldades encontradas na cultura jornalística a respeito do tratamento preventivo dos assuntos. A partir da perspectiva da percepção de riscos, reforça-se a ideia de que o jornalismo participa como um dos fatores que podem gerar ação frente às questões ambientais em razão de seu poder amplificador ou, pelo contrário, contribuir para a não compreensão dos riscos, quando os ignora. Após revisão de literatura, verificam-se os silenciamentos na cobertura dos transgênicos, da mineração em Mariana (MG) e da CMPC em Guaíba (RS). Dentre as considerações, aponta-se que os próprios valores que guiam a construção da notícia impedem a emergência de um jornalismo comprometido com a percepção dos riscos, fato este que dificulta o enfrentamento dos mesmos. Logo, argumenta-se que as mudanças da sociedade devem implicar também em transformações das lógicas jornalísticas.

\section{ABSTRACT}

This article proposes a debate about the role of journalism in giving visibility to environmental risks, although we know the difficulties encountered in the journalistic culture regarding preventive treatment of environmental issues. From the perspective of risk perception, the idea that is reinforced is that journalism participates as one of the factors that can generate action on environmental issues because of its amplifying power or, on the contrary, can contribute to the lack of understanding when risks are ignored. After reviewing the literature, the blackouts in the coverage of transgenic crops, mining in Mariana (in state of Minas Gerais) and CMPC in Guaíba (in the state of Rio Grande do Sul) are verified. Among the considerations, it is pointed out that the very values that guide the construction of the news prevent the emergence of a journalism committed to the perception of risks, a fact that makes it difficult to face them. Therefore, it is argued that changes in society must also imply transformations in journalistic logics. 


\section{INTRODUÇÃO}

Este texto discute as relações existentes entre o Jornalismo e a cobertura dos riscos, amparando-se no quadro teórico sobre percepção dos riscos no qual os meios de comunicação exercem fundamental relevância, pois são estes que os amplificam ou os silenciam. Os riscos ambientais tendem a ser complexos e, muitas vezes, intangíveis, características que dificultam o processo de construção da notícia. Contudo, é por meio desta comunicação que os jornalistas podem gerar alertas e chamar atenção da população para um debate público, que tenha perspectiva preventiva e de adaptação aos efeitos que já não podem ser mais revertidos.

A partir de pesquisa bibliográfica e de casos que exemplificam nossa inquietação, desenvolve-se uma reflexão sobre como os jornalistas desempenham esse papel estratégico no âmbito da comunicação dos riscos e de como podem colaborar para a disseminação de propostas para esclarecer e minimizar determinados riscos. Salienta-se aqui aquilo que não é dito, ou seja, os silenciamentos do Jornalismo em relação aos riscos ambientais. Buscase debater como esse ocultamento de fatos ou conexões pode interferir na percepção e compreensão dos problemas ambientais contemporâneos e a razão pela qual o Jornalismo não cobre os riscos ambientais de forma sistemática.

A primeira seção debate as dificuldades do fazer jornalístico diante dos riscos ambientais, evidenciando o modo de se fazer Jornalismo a partir dos critérios de noticiabilidade e da ênfase na ação dos acontecimentos (em detrimento da prevenção). Em seguida, apresenta-se o aporte da percepção de risco, com ênfase no aspecto social (Lima, 1998; 2005), oriundo da Psicologia Social, e sua relação com o papel desempenhado pela mídia e, de forma específica, pelo Jornalismo, por meio do quadro teórico da amplificação social do risco (Kasperson e outros, 1988).

A terceira parte trata dos silenciamentos da cobertura jornalística no âmbito da Modernidade (Giddens, 1991; Beck, 2010) sobre meio ambiente, destacando os riscos. Nesta perspectiva, Jornalismo e riscos ambientais são apresentados como frutos distintos de um mesmo processo, a Modernidade. Na seção apontam-se também alguns exemplos emblemáticos da imprensa brasileira, como a cobertura do desastre ocorrido em 2015 na cidade de Mariana (MG), a forma como a questão da liberação do plantio dos transgênicos foi construída pela imprensa de referência no âmbito do setor rural, e o fato de os dois principais jornais do Rio Grande do Sul, por interesses econômicos, não discutirem os riscos da nova fábrica da CMPC Celulose Riograndense. Por fim, tecem-se as considerações finais de modo a entrelaçar ainda mais o referencial 
teórico do Jornalismo com a preocupação associada à necessidade de visibilizar os riscos ambientais.

\section{JORNALISMO E RISCOS AMBIENTAIS: DESAFIOS DE UM FAZER}

Por que as notícias são como são? Qual o papel do Jornalismo como instituição de uma democracia e do jornalista como profissional? Tais perguntas das teorias do Jornalismo precisam ser reformuladas diante da magnitude das alterações ambientais globais e dos seus impactos regionais e locais. Por que as notícias ambientais são como são? Qual o papel do Jornalismo como instituição e do jornalista como profissional diante dos riscos ambientais?

Quatro fatores, segundo Garcia (2006), estão geralmente presentes nas notícias ambientais: boa parte dos temas está associada a processos longos (caso, por exemplo, da mudança do clima, da extinção de espécies, da poluição hídrica, etc.); incerteza científica (a dúvida é da natureza do método científico); complexidade técnica (a apresentação dos problemas e das soluções exige uma terminologia de diversos campos que precisa ser explicada em linguagem simples); e a noção de risco: "O risco é um poderoso chamariz para notícias" (Garcia, 2006, p.23). Na mesma linha, Traquina (2002, p. 187) entende que a morte é um valor-notícia importante para o Jornalismo; em termos de riscos ambientais pode-se pensar na morte por poluição, na morte ocasionada por desastres, na morte de espécies em extinção, na morte de uma civilização e até na morte do planeta. Mais dois fatores ainda devem ser acrescentados aos quatro já ditos (processos longos, incerteza científica, complexidade técnica e noção de risco): quase todas as pautas ambientais mexem com os interesses econômicos dos poluidores (muitos deles anunciantes de veículos jornalísticos e patrocinadores de iniciativas nas comunidades onde atuam); um problema ambiental sempre gera algum tipo de conflito social.

De forma mais específica, Kitzinger e Reilly (2002) lembram que, apesar dos riscos (e aqui inclui-se a possibilidade de morte) serem elementos que poderiam alavancar o interesse jornalístico para sua cobertura, há uma seletividade sobre quais deles serão expostos. A noticiabilidade do risco não é a mesma para todos os tipos de risco. E quando a origem do risco é um grande patrocinador de empresas jornalísticas, caso da Vale e da Monsanto no Brasil, e da CMPC Celulose no Rio Grande do Sul, o silenciamento aumenta por autocensura.

A transformação de um fato ou acontecimento em notícia e/ou reportagem depende de critérios de noticiabilidade que, segundo Silva (2014), são uma soma de três conjuntos ou de três instâncias: a da origem do fato, a do tratamento do fato e a da visão do fato. Na origem do fato acontece a 
seleção primária a partir dos valores-notícia. Para Traquina (2002), entre os principais valores-notícia estão: a notoriedade; a proximidade; a relevância; a novidade; a notabilidade, com diferentes registros (quantidade de pessoas, a inversão do normal, o insólito, a falha, o excesso/escassez); o inesperado e o conflito ou a controvérsia. No entanto, para um fato ou acontecimento virar notícia não bastam valores-notícia. Nesta segunda instância dos critérios de noticiabilidade, a do tratamento dos fatos, ocorre a seleção hierárquica. Além dos valores-notícia, os constrangimentos organizacionais (dentre os quais estão os interesses econômicos) e a cultura profissional também são levados em consideração no processo de construção da notícia. Ainda no entendimento de Silva (2014), é na terceira instância dos critérios de noticiabilidade que estão os fundamentos ético-epistemológicos, ou seja, a visão de mundo dos jornalistas, "compreendendo conceitos de verdade, objetividade, interesse público, imparcialidade, que orientam inclusive as ações e intenções das instâncias ou eixos anteriores" (Silva, 2014, p.53).

Os temas salientados pelo Jornalismo tendem a entrar na agenda pública (McCombs, 2009). Temas que não são agendados dificilmente terão existência pública. "Fixar a agenda é fixar o calendário dos acontecimentos. É definir o que é importante e o que não é. [...] É criar o clima no qual será recebida a informação. É fixar não só o que vai ser discutido, mas como e por quem" (Barros Filho, 2008, p. 159).

Os seis fatores presentes nas notícias ambientais - processos longos, incerteza científica, complexidade técnica, noção de risco, interesses econômicos e conflitos sociais - dificultam o agendamento e, por consequência, a problematização dos temas ambientais na esfera pública. Kitzinger e Reilly (2002) apontam que, embora haja preocupação dos jornalistas, os temas de risco não conseguem encorajar uma cobertura por três razões: 1) a incerteza científica por si só, típica dos riscos, não atrai os jornalistas, que buscam concretudes; 2) se não há uma medida do governo ou outra instituição em relação à prevenção, é muito provável que o risco seja ignorado e, portanto, não percebido - o que desencoraja o valor-notícia da estória; e 3) o risco refere-se a projeções e os jornalistas trabalham com acontecimentos - a manifestação do risco é um gatilho necessário para a produção jornalística.

É, por isso, que riscos ambientais são geralmente apresentados somente durante os desastres e catástrofes - neste momento já deixaram de ser projeções e passaram a ser acontecimentos reais, muitas vezes com mortes. "O campo jornalístico tem maiores dificuldades na abertura de problemáticas. [...] O ritmo do trabalho jornalístico exige ênfase sobre acontecimentos e não sobre problemáticas" (Traquina, 2002, p.191). Sem um acontecimento catastrófico, 
os riscos ambientais tendem a ser silenciados. Alsina (2009) destaca entre os elementos que determinam o que vira notícia a existência de uma variação perceptível e de uma imprevisibilidade. Este imperativo da variação bloqueia, de acordo com Benetti (2010), a abordagem jornalística de problemas estruturais da sociedade.

A perversidade dessa lógica [da variação como índice do acontecimento jornalístico], que contra qualquer argumento plausível mantém-se como estruturante do discurso jornalístico, é que grandes fenômenos sociais, cujo interesse público não poderia ser questionado sem constrangimento, geralmente não têm lugar no jornalismo porque se estabeleceram, historicamente, como invariantes. São os casos da fome, das desigualdades e das injustiças sociais, que contemporaneamente costumam ser percebidas como "parte do sistema"(Benetti, 2010, p.146).

Os riscos ambientais também podem fazer parte desta lista de pautas invisíveis do Jornalismo citada por Benetti (2010). Um tema ambiental costuma ser problematizado jornalisticamente somente após um desastre, caso, por exemplo, do rompimento da barragem de rejeitos da empresa Samarco no município de Mariana (MG) em 2015 ou da escassez hídrica que assolou recentemente São Paulo. Devido à incapacidade de ir além do rompimento da rotina (novidade) como valor-notícia, problemas da atualidade, entendidos como "normais", são frequentemente silenciados. É preciso ressaltar que os valores-notícia, ainda que sejam frutos de uma época determinada, são retroalimentados pelos próprios veículos jornalísticos. Isto fica claro em um fenômeno descrito por Traquina (2005, p.202) através de duas expressões, o jornalismo de matilha (pack journalism) e a cobertura massiva e frenética (media frenzy) em torno de um único acontecimento. Quando um veículo descobre um tema importante e de repercussão, todos os demais ("lobos") tendem a correr atrás da mesma história. O jornalismo de matilha e a cobertura frenética, frequentes em grandes desastres, criam consensos e silenciamentos jornalísticos em torno de determinados temas. "A existência de um modo de ver, modo de agir, e modo de falar estabelece um elo de ligação bastante forte entre os membros da diáspora jornalística" (Traquina, 2005, p. 202).

Para Alsina (2009), a produção da notícia é um processo complexo que se inicia com um acontecimento. Acontecimento que sempre é um fenômeno social, determinado histórica e culturalmente. Como é o sujeito observador quem lhe confere sentido, toda forma de enxergar e ressaltar algo em um acontecimento 
é também uma forma de ocultar algo. "A sociedade da mídia poderia ser definida como uma sociedade que 'faz acontecer'" (Alsina, 2009, p. 126).

Segundo Quéré (2005, p. 59), há acontecimentos que "[...] ocorrem independentemente da nossa vontade e nos caem em cima contra toda a expectativa e aqueles cuja ocorrência provocamos e, melhor ou pior, controlamos, na maior parte das vezes com objetivos estratégicos". Um acontecimento, que afeta um sujeito (França, 2012), interrompe uma rotina e desorganiza o presente, gerando uma inquietação: e agora? Um acontecimento pode ser entendido como fim, mas também como começo. Fim porque pode ser compreendido em sua trama causal, desde sua origem; começo porque faz surgir possibilidades, projeta um novo sentido sobre o mundo. "Sentido do qual ele será a origem" (Quéré, 2005, p. 67).

Para produzir uma narrativa acerca de um acontecimento, que ao ser narrado passa a existir também como discurso, o jornalista antes precisa observá-lo e interpretá-lo. Na narrativa jornalística construída sempre há, implícita ou explicitamente, uma interpretação. Tal narrativa jornalística só é possível, portanto, através da intervenção de um sujeito interpretante, o jornalista, que tem como tarefa “[...] a observação do notável num mundo em perpétua mudança. [...] E, mesmo sem que o procure, pode acontecer que a sua informação tenha por efeito influir no curso dos acontecimentos" (Cornu, 1999, p.331-332). A observação, a interpretação e a narração, segundo Cornu (1999), são as três ordens da informação jornalística. O toque principal que caberia ao jornalista, no entendimento de Beltrão (1959, p.81), seria "acertar na interpretação do tema".

Para interpretar acertadamente os grandes temas ambientais é preciso romper o silêncio construído em torno dos riscos ambientais. Apesar dos condicionamentos sistêmicos, que são muitos (cultura organizacional, mercado de trabalho instável, pressão dos anunciantes poluidores, interesses privados dos proprietários), os jornalistas sempre têm, em maior ou menor grau, dependendo do local de trabalho, uma margem de liberdade para atuar de acordo com a sua consciência acerca da função social do Jornalismo.

Segundo Benetti (2013, p.45), muitas são as maneiras de o Jornalismo exercer o seu poder hermenêutico: “[...] ao destacar temáticas que devem ser consideradas relevantes, ao conceder poder de fala a grupos e ideologias, ao instituir angulações e quadros interpretativos para perceber, avaliar e compreender relações". Esta realidade construída pelo Jornalismo é um dos discursos possíveis sobre o real. Este real jornalístico (discursivo) é construído através de uma relação dialética entre objetividade e subjetividade (Meditsch, 2010). É um discurso que emerge entre outros discursos já ditos sobre o real. A 
intersubjetividade é a condição de possibilidade do discurso (jornalístico), pois ele não tem como ser fruto de uma subjetividade única (nem isolada e nem transcendente). $O$ Jornalismo está submerso neste mundo intersubjetivo que $o$ afeta, mas também é afetado por ele. O poder do Jornalismo está no efeito de sentido que o seu discurso (intersubjetivo) produz.

A percepção do risco ambiental depende, em parte, deste efeito de sentido construído pelo Jornalismo. As teorias do risco concedem um papel crescente à mídia (Kitzinger e Reilly, 2002), pela visibilidade que promove a riscos que, de outra forma, poderiam ser ignorados. Contudo, é preciso se questionar: como ela atua? Como o risco é uma construção social, no qual questões culturais irão selecionar aqueles que serão naturalizados por cada sociedade, é válido questionar quem definirá o que é risco e por quais razões, já que nem sempre os diretamente afetados têm voz neste debate.

\section{JORNALISMO E PERCEPÇÃO DE RISCOS}

A percepção é compreendida neste texto segundo a perspectiva construcionista, na qual esta é uma construção mental, fruto de práticas sociais. Em outras palavras, a percepção é um conceito que envolve o processamento de quadros interpretativos, no qual o sujeito é ativo e o contexto simbólicodiscursivo se faz fundamental (Loose, 2016). Da mesma forma se conceituam os riscos: são construções sociais, como afirmam Douglas e Wildavsky (2012). Dessa forma, o reconhecimento do risco ocorre através de um processo social, ligado à confiança e medo, e cercado por valores e fatores, que dependem dependem do contexto, o que faz com que determinadas pessoas percebam um certo risco e outras não. As percepções de risco variam bastante, mas possuem elementos que desencadeiam tais percepções que podem ser mais ou menos evidentes tanto individualmente quanto socialmente.

É importante dizer que há uma relação entre a percepção de risco e a tomada de decisão, ainda que esta não seja automática ou fácil de ser detectada. Os primeiros estudos na área de percepção de risco, nos anos 1950, estavam centrados em uma visão mais racional, de como as pessoas processavam as informações do risco. Assim, a visão de mundo dos não especialistas era ignorada, já que eles não detinham conhecimento específico para agir de forma coerente frente ao risco.

Entretanto, os cientistas notaram que a tomada de decisão está aliada não apenas ao sistema racional, mas também às experiências, emoções, sentimentos (Slovic e outros, 2004). A partir de então a identificação de risco começou a ser vista como um fenômeno cultural e social (Lima, 1998), no qual uma série de 
fatores se entrelaçam e se diferenciam de sujeito para sujeito - não apenas a informação correta a respeito do risco. Para Lima (1998, p.16), a percepção de risco, "[...] não pode ser compreendida sem considerarmos a sua associação com outras representações significativas para os sujeitos e sem considerarmos também o posicionamento social desses mesmos actores sociais".

Há estudos que mostram que o gênero (Lima, 2005), a situação econômica (Inglehart, 1995) e a proximidade geográfica com o risco (Lima, 2005), só para citar alguns exemplos, são questões que interferem em como os sujeitos são capazes de perceber o risco. Ao trazerem os riscos como um dos aspectos centrais da Modernidade, Giddens (1991) e Beck (2010) levantam outras condições associadas à percepção do risco, como a própria discussão sobre a (des) confiança na ciência e no Estado, tendo em vista o cenário atual de incertezas e hiperconexões, no qual as mudanças locais acarretam transformações globais em ritmo acelerado.

Apesar de não se constituírem como uma novidade, é a partir do advento da Modernidade que os riscos (e sua percepção e enfrentamento) assumem uma condição central na sociedade. Aqui entende-se que a Modernidade, nos termos de Giddens (1991, p. 11) , "[...] refere-se a estilo, costume de vida ou organização social que emergiram na Europa a partir do século XVIII e que ulteriormente tornaram-se mais ou menos mundiais em sua influência". Portanto, esta seria fruto da intensificação do modo de produção fabril: é necessário, então, ponderar que a Modernidade assim compreendida trata-se de um fenômeno absolutamente situado espacial e temporalmente, cujas consequências ressoaram no planeta de formas diversas'.

A reflexividade advém do fato de que a Modernidade é reiteradamente questionada, o que a torna um projeto em permanente construção. Em diálogo com o que Giddens (1991) conceitua como Modernização Reflexiva, Beck (2010) teoriza sobre a emergência de uma sociedade pós-industrial, a "Sociedade de Risco", amplamente caracterizada pela incerteza. Ao observar o desenvolvimento das forças produtivas, o autor passa a colocar em dúvida a possibilidade da continuidade da vida no planeta. Nesta etapa da Modernidade que estaríamos vivendo, a ciência é o principal elemento a ser considerado, visto que ela é simultaneamente produtora e produto dos riscos.

$\mathrm{Na}$ construção de seu argumento, Beck (2010) une elementos de abordagens realista e construcionista, numa tentativa de superar uma suposta

1 É, talvez, este o principal motivo pelo qual teóricos da modernidade têm sido criticados hoje: seu projeto é demasiado eurocentrado, não dando conta de modos de vida outros. Os principais críticos a esta concepção são os teóricos que partem de abordagens pós (ou des)coloniais, para os quais, em linhas gerais, a Modernidade e a colonialidade estão inexoravelmente imbricadas. 
antinomia entre elas: não se nega a materialidade dos riscos ao passo que não dá a ela a centralidade da análise. Isto é: "A síntese da posição de Beck é a de que os riscos existem, mas a sua transformação depende de como são percebidos socialmente."(Guivant, 2002, p. 76). Tal perspectiva, portanto, coloca em destaque o diálogo necessário entre leigos e peritos na produção e enfrentamento dos riscos, ou, conforme Rotondaro:

[...] na medida em que eles [os riscos] são industrialmente produzidos, Beck compreende que eles também são politicamente reflexivos, uma vez que são produto de decisões. Riscos são produtos das ações e omissões humanas, num contexto de forças produtivas altamente desenvolvidas. Como consequência, os riscos tornam-se motor da autopolitização da modernidade na sociedade industrial, ainda que o conceito, o lugar e o meio da política mudem (Rotondaro, 2012, p. 153-154).

Assim, com a emergência da Sociedade de Risco, a natureza, que é transfigurada pela ação humana (não haveria mais, portanto, a "natureza pura"), é também socializada (pois todos são corresponsáveis por ela, assim como todos sofrem as consequências dos riscos). Nesse sentido, os riscos não são causalidades, mas sim devem ser entendidos como internalizados pelo sistema.

Considerando o caráter social dos riscos, evidencia-se a urgência de um Jornalismo que os considere. A comunicação do risco, área ampla da qual o Jornalismo pode fazer parte, já discute que aspectos emocionais e contextuais de cada público devem ser trabalhados a fim de obter mais êxito na explicação de nexos abstratos e completos, associados aos riscos. O Jornalismo, de forma específica, calcado nos seus princípios de credibilidade e de serviço ao interesse público, deve construir notícias sobre riscos que sejam próximas do repertório cultural de seus públicos, de forma a contribuir com a percepção não apenas do risco, mas de sua urgência e, quiçá, de sua necessidade de enfrentamento.

A mídia é posta como uma peça-chave na construção do risco por Veyret (2007). Loose (2016, p. 125) destaca, a partir do esquema de Veyret (2007), que "o Jornalismo tanto se alimenta dos riscos para elaborar seus produtos (textos), como pode promover riscos em função de projeções/informações desproporcionais". Isto é, os riscos possuem potencial de noticiabilidade para o Jornalismo, mas, ao mesmo tempo, percepções de risco podem ser representadas pela mídia em razão da escolha de alguns enquadramentos ou fontes, podendo distorcer a compreensão do mesmo. 
Neste contexto cabe falar do quadro conceitual da amplificação dos riscos, no qual Kasperson e outros (1988) buscaram entender como dados acontecimentos atuavam nos processos sociais, psicológicos e culturais de forma a atenuar ou acentuar a percepção de risco, além de descrever os efeitos deles decorrentes em diferentes níveis (individual, social, político, econômico, ambiental, etc.). Apesar do peso dado aos meios de comunicação neste modelo (bem que interferem por meio da recorrência de assuntos, da dramatização, do silenciamento ou da exposição enfática de controvérsias, por exemplo), sublinhase que esta não é uma situação causal. Os receptores também são ativos e podem interpretar estas manifestações de formas diferentes, inclusive ignorá-las.

Reconhece-se, assim, os limites do Jornalismo enquanto influenciador das percepções de risco. Wahlberg e Sjoberg (2000) afirmam que as informações provenientes da mídia atingem pouco a percepção do risco em nível pessoal, posto como um dos mais fortes para o reconhecimento do risco. Por outro lado, McCombs (2009) aponta que se a experiência pessoal não trouxer elementos que possam ajudar os sujeitos a formar uma opinião, maior será sua dependência das notícias. Tratando-se de riscos ambientais esta colocação se faz pertinente, já que esses são apresentados, na maioria das vezes, sob o aspecto global e, portanto, distante do cotidiano dos públicos.

\section{SILENCIAMENTOS E NÃO DITOS}

Se a Modernidade é marcada pela emergência da Ciência e suas (in) certezas, é também neste período que se funda o Jornalismo tal qual se conhece. Isto posto, pode-se considerar que também os critérios de noticiabilidade e os modos de produção - por mais que se atualizem e se repensem diante de novas tecnologias e da complexificação social - são tributários de uma lógica moderna. Assim, o Jornalismo e a produção/percepção de riscos se fundam num mesmo tempo e espaço, portanto, crê-se que também as notícias conformam riscos, os legitimando ou os silenciando.

Conforme já abordado, muitos dos riscos ambientais têm caráter etéreo, isto é, embora possuam origens e efeitos na materialidade, são de difícil observação, como é o caso do risco climático, que pode ser caracterizado como um risco global, invisível, incerto, difuso e não palpável. Do mesmo modo, em geral não podem ser antevistos e mensuráveis, o que remonta à dificuldade do Jornalismo de lidar com o incerto.

O Jornalismo moderno parece preocupar-se com fatos, isto é, com o acontecimento já dado. Esta obsessão pelo real (que está conectada à busca pela verdade, como se esta fosse apenas uma) é fundante do próprio ofício. 
Nesse mesmo sentido, a busca do Jornalismo por acontecimentos (em especial catástrofes e desastres) impede que se cubram processos mais longos e não menos importantes. Um exemplo disto é a abordagem acerca da liberação dos transgênicos, hoje já naturalizada, ainda que inúmeros pesquisadores e organizações da sociedade civil apontem riscos de diversas ordens, indo do ambiental ao econômico. Tendo como objeto empírico a revista Globo Rural, um dos veículos impressos voltado ao setor agropecuário de maior influência no Brasil, Camana (2015) buscou analisar os sentidos produzidos sobre a propriedade intelectual e a transgenia no Brasil durante dez anos, a partir da liberação da venda da primeira safra de soja transgênica, em 2003. Em sua análise, fica evidente a não abordagem dos riscos potenciais deste empreendimento, como o monopólio dos meios de produção por parte das empresas multinacionais fornecedoras de sementes, a própria incerteza em relação aos possíveis danos à saúde dos consumidores e a degradação da natureza no entorno das lavouras. Isto é, as notícias e reportagens encontradas, em sua maioria, possuem um caráter de divulgação desta nova tecnologia, sempre ressaltando o seu potencial produtivo e de inovação, o que permitiria ao Brasil figurar entre os maiores produtores agrícolas do mundo. Apesar do próprio campo científico à época (2003-2013) estar permeado de tensões e conflitos entre pesquisadores e suas versões, toda esta incerteza quanto aos Organismos Geneticamente Modificados (OGMs) não foi coberta pela imprensa na proporção adequada.

Nestamesma pesquisa, fica evidentequea transgenia só se torna noticiável quando surge uma nova controvérsia ou algum conflito antigo é reaquecido: as maiores e mais completas reportagens encontradas foram publicadas entre 2003 e 2005, período em que se discutiu intensamente a liberação dos OGMs no Brasil - primeiro da safra, depois do plantio. Nos anos subsequentes, pouca ou nenhuma problematização foi feita, o que sugere que - para a revista - os riscos se encerraram quando da permissão do cultivo: é como se algo que é do domínio tecnocientífico fosse encerrado por uma decisão que é política. Assim, as inúmeras denúncias da sociedade civil e a suspeição de cientistas acerca desta tecnologia são ignoradas sistematicamente pelo Jornalismo de referência neste setor. Nos últimos anos, inclusive, diversos estudos têm sugerido o potencial cancerígeno dos OGMs, além de colocarem em xeque a alegação de que o prometido aumento de produtividade por esta tecnologia não se confirma a longo prazo (Ferment, 2011).

Do mesmo modo, os valores-notícia nos quais se ancora o Jornalismo fazem com que se amplifiquem as discussões após a ocorrência de desastres, os quais talvez pudessem ter sido evitados caso as notícias incorporassem a 
perspectiva dos riscos em seu fazer. Esta afirmação fica patente quando se retoma a cobertura feita do rompimento da barragem de rejeitos da Samarco em Mariana (MG), ocorrido em novembro de 2015. Este acontecimento - que é tido como o maior acidente mundial do tipo - foi, num primeiro momento, abordado pela via da catástrofe, daquilo que não se espera e, portanto, não se impede. Esta abordagem se justifica e intensifica com o testemunho emocionado de sobreviventes e com o registro de imagens chocantes, como - por exemplo - a lama invadindo o oceano. Caso do Jornal Nacional, que primeiro enquadrou a destruição, o sofrimento e as perdas e depois passou a cobrir a investigação dos órgãos oficiais (Feitosa e Alves, 2017), sem protagonismo jornalístico. Antes da tragédia, a Vale publicou anúncios em revistas nacionais apresentando o Complexo de Mariana como modelo, sem qualquer investigação acerca da veracidade das informações publicitárias por parte das revistas que publicaram os anúncios de página dupla.

Assim, concorda-se com Amaral (2013, p. 76), quando a autora defende que: "As catástrofes são um fenômeno discursivo e cultural. Sua cobertura está presidida pela tendência ao catastrofismo, ao sensacionalismo e pela preponderância da imagem sobre a análise". Em síntese: ao silenciar os riscos, o Jornalismo não só se prepara para cobrir catástrofes, mas ele próprio é cúmplice do desastre.

Esta cumplicidade ocorre não apenas nos grandes desastres, como no caso do rompimento da barragem de rejeitos da Samarco em Mariana (MG), mas também na poluição permanente causada pelo lançamento de efluentes industriais em corpos d'água utilizados para abastecimento público. Caso emblemático é o da CMPC Celulose Riograndense, quadruplicada em 2015 no município de Guaíba (RS), aumentando em mais de três vezes o lançamento de resíduos no lago utilizado como fonte de água potável para a capital gaúcha. Os riscos ambientais da fábrica de capital chileno - a contaminação do lago Guaíba e o passivo ambiental do grupo chileno em outros empreendimentos são silenciados pelos dois principais jornais de Porto Alegre (RS) por interesses econômicos. O presidente da empresa é colunista do Zero Hora, jornal que publicou apenas uma reportagem sobre os riscos da nova fábrica (Melo, 2015), apesar de já ter ocorrido diversos acidentes desde a sua inauguração, registrados apenas como notícia. Ao enfatizar em suas páginas os benefícios econômicos do empreendimento, o risco ambiental é silenciado e, assim, excluído da agenda pública. No Correio do Povo, segundo jornal em importância no Rio Grande do Sul, a cobertura dos riscos é ainda menor. A CMPC é anunciante dos dois jornais e está pagando (Celulose Riograndense..., 2015) a digitalização de todo o acervo histórico do Correio do Povo, fundado em 1895 por Caldas Júnior. 
Faz-se urgente, também, que o Jornalismo repense o papel da ciência, que hoje tem o (quase) monopólio da definição de riscos nas páginas informativas, além de ser comumente apontada como a principal instituição capaz de enfrentar os mesmos. Como afirmam Loose e Camana:

No caso específico de riscos, as fontes com expertise dominam as vozes das notícias que envolvem ameaças ou incertezas. Estes indivíduos foram legitimados na modernidade como aqueles capazes de gerenciar todos os problemas possíveis, ainda que a verdade não seja esta (Loose e Camana, 2015, p. 124).

A título de exemplo, pode-se evocar a situação da usina nuclear Angra I, construída quando da ditadura militar na Praia de Itaorna: itaorna, na língua dos guarani que ali habitavam, quer dizer pedra podre. Assim, o conhecimento tecnocientífico empregado ignorou os riscos de se construir uma usina atômica (cujo funcionamento já guarda inúmeras controvérsias) em uma área potencialmente fissurada geologicamente, cuja toponímia local já alertava. Quanto a isto, a proposta do Jornalismo Ambiental ${ }^{2}$ é certeira ao defender a plurivocalidade e o fim da centralidade das fontes ditas "especializadas".

Para além das consequências, as causas e as soluções precisam ser discutidas através de uma diversidade de fontes. Esteéo compromisso ético que deve ser assumido pelos jornalistas diante de uma crise socioambiental e de um planeta com mudanças ambientais globais com impactos econômicos e sociais cada vez maiores (Belmonte, 2015, p. 124).

Destaca-se, neste contexto, que, embora os autores deste texto compartilhem da relevância das especificidades do Jornalismo Ambiental, acredita-se que já é hora de expandir suas preocupações para todo o campo do Jornalismo frente os desafios cada vez mais urgentes que se sobrepõem na sociedade contemporânea. Entende-se que o cuidado discutido no âmbito desta interface deve ampliar-se e ser internalizado por todas as áreas e especialidades

2 Ressalta-se que a concepção de Jornalismo Ambiental é diferente da noção de cobertura jornalística de meio ambiente ou de riscos ambientais, já que a primeira expressão carrega um arcabouço teórico que extrapola a perspectiva comum da prática jornalística. Para conhecer mais, procurar trabalhos desenvolvidos pelo Grupo de Pesquisa Jornalismo Ambiental (UFRGS/ CNPq) disponíveis no site <https://jornalismoemeioambiente.com/> 
jornalísticas, não devendo ficar restrito somente aos interessados pelas problemáticas ambientais.

Uma nova maneira de olhar o mundo é o que se espera do Jornalismo por meio de uma ação engajada e profissional. Enquanto o econômico continuar predominante sobre o social e o ecológico, os riscos ambientais continuarão sendo silenciados.

Além disso, quando a imprensa alerta sobre os riscos, desencadeia processos tanto de ação individual (pois contribui para a percepção de algo antes desconhecido, etapa inicial para o enfrentamento de qualquer problema) quanto de decisões de cunho político e econômico, ao dar visibilidade àquilo que antes - geralmente por interesses de poucos - estava sendo ocultado. $O$ Jornalismo, apesar de seus limites, pode colaborar com a construção de quadros interpretativos sobre os riscos ambientais mais contextualizados e condizentes com a perspectiva da prevenção. Para isso, a compreensão de sua dimensão amplificadora ou atenuadora dos riscos pode ser o gatilho desta mudança.

\section{ROMPENDO COM O SILÊNCIO: JORNALISMO PARA NOVOS TEMPOS}

Buscou-se aqui trazer elementos para a discussão da (não) cobertura dos riscos ambientais pelo Jornalismo. Para tanto, dialogou-se com referenciais teóricos a respeito da produção e percepção de riscos na Modernidade e das teorias do Jornalismo, em especial a respeito da construção da notícia. Como pressuposto estava a noção de que o Jornalismo em geral silencia riscos ambientais, dada a dificuldade de apreendê-los a partir de um modo de produção guiado pela novidade e pelo factual. Do mesmo modo, a inexistência de imagens fortes e comoventes inviabiliza a cobertura sistemática da previsão das catástrofes, visto que os riscos são sempre possibilidades que antecedem o acontecimento procurado pelos jornalistas e, muitas vezes, são invisíveis e multifacetados, o que dificulta o fazer tradicionalmente instituído nas redações.

Assim, é possível apontar que os próprios valores que guiam a construção da notícia impedem a emergência de um Jornalismo comprometido com a percepção dos riscos, fato este que dificulta o enfrentamento dos mesmos. Em oposição a esta situação, os aportes do Jornalismo Ambiental tornamse uma possibilidade de transformação das práticas que vigoram, através da incorporação da complexidade e da incorporação de saberes até então ignorados. Contudo, este deve extravasar o espaço de uma especialidade, tentando ser um aspecto de interesse de todos os setores.

Diante da complexificação das relações sociais e do refinamento crescente das inovações científicas, aponta-se que (como sugere a reflexividade 
moderna) os valores-notícia que hoje orientam a seleção de pautas sejam urgentemente revistos - sob pena de um fazer jornalístico pouco responsável social e ambientalmente. Mais que a reprodução sistemática de valores de noticiabilidade fundados num paradigma centrado na insuspeita da técnica e da ciência, o Jornalismo deve perceber que as certezas que veicula são produzidas e, portanto, sempre situadas e mais ou menos provisórias.

Entende-se que a espetacularização da morte deve dar lugar à defesa da vida e que informações mais contextualizadas e associadas ao dia a dia das pessoas devem ser produzidas de modo a não silenciar os muitos riscos que perpassam a sociedade. Para que haja uma "democratização do risco", Kitzinger e Reilly (2002) afirmam que não bastam os trabalhos de grupos de pressão ou maior regulamentação, mas transformações culturais, políticas e materiais na sociedade e nas indústrias midiáticas devem ser desencadeadas. Mudanças no fazer jornalístico são exigidas para dar conta de seu papel social na contemporaneidade.

O enfrentamento dos riscos não é possível sem a percepção de que ele realmente existe. Quando o Jornalismo se omite ou desconsidera sua potencialidade de visibilizar tais questões, assume que rompeu o compromisso com o interesse público.

\section{Referências}

ALSINA, Miquel Rodrigo. A construção da notícia. Petrópolis, RJ: Vozes, 2009.

AMARAL, Márcia Franz. Os testemunhos de catástrofes nas revistas brasileiras: do medo individual à paternização midiática. Contracampo, v. 26, p. 71-86, 2013.

BARROS FILHO, Clóvis de. Ética na comunicação. 6. ed. São Paulo: Summus, 2008.

BECK, Ulrich. Sociedade de risco: rumo a uma outra modernidade. São Paulo: Editora 34, 2010.

BELMONTE, Roberto Villar. A construção do discurso da economia verde na revista Página 22. 2015. 179 f. Dissertação (Mestrado em Comunicação e Informação) - Faculdade de Biblioteconomia e Comunicação, UFRGS, Porto Alegre, 2015.

BELTRÃO, Luiz [1959]. Iniciação à Filosofia do Jornalismo. São Paulo: Edusp, 1992.

BENETTI, Marcia. O jornalismo como acontecimento. In: ; FONSECA, Virginia Pradelina da Silveira (Org.). Jornalismo e acontecimento: mapeamentos críticos. Florianópolis: Insular, 2010. p.143-164. 
Revista e jornalismo: conceitos e particularidades. In: TAVARES, Frederico de Mello Brandão; SCHWAAB, Reges. (Org.). A revista e seu jornalismo. Porto Alegre: Penso, 2013, p. 44-57.

CAMANA, Ângela. Discursos sobre a Revolução Biotecnológica: Sentido e memória em textos da Globo Rural. 2015. 168 f. Dissertação (Mestrado em Comunicação e Informação) - Faculdade de Biblioteconomia e Comunicação, UFRGS, Porto Alegre, 2015.

"Celulose Riograndense é parceira na preservação da história do povo gaúcho e brasileiro". 2015. Disponível em: http://www.celuloseriograndense.com.br/ noticias/celulose-riograndense-e-parceira-na-preservacao-da-historia-dopovo-gaucho-e-brasileiro. Acesso em: 20 maio 2017.

CORNU, Daniel. Jornalismo e verdade: para uma ética da informação. Lisboa: Instituto Piaget, 1999.

DOUGLAS, Mary; WILDAVSKY, Aaron. Risco e cultura: um ensaio sobre a seleção de riscos tecnológicos e ambientais. Rio de Janeiro: Elsevier, 2012.

FEITOSA, Sara Alves; ALVES, Giseli Pereira. Os enquadramentos de uma cobertura: tragédia de Mariana. Vozes e Diálogo, v. 16, p. 5-18, 2017.

FERMENT, Gilles. Análise de risco das plantas transgênicas: princípio da precaução ou precipitação? In: ZANONI, Magda; FERMENT, Gilles. Transgênicos para quem?: Agricultura, Ciência e Sociedade. Brasília: MDA, 2011. p. 93-138.

FRANÇA, Vera. O acontecimento e a mídia. Galaxia, São Paulo, n. 24, p. 10-21, dez. 2012. Disponível em: http://revistas.pucsp.br/index.php/galaxia/article/view/12939. Acesso em: 25 jul. 2016.

GARCIA, Ricardo. Sobre a terra: um guia para quem lê e escreve sobre ambiente. Lisboa: Público, 2006.

GIDDENS, Anthony. As consequências da modernidade. São Paulo: Editora Unesp, 1991.

GUIVANT, Julia. Contribuições da Sociologia Ambiental para os debates sobre desenvolvimento rural sustentável e participativo. Estudos Sociedade e Agricultura, n. 19, p. 72-88, out. 2002.

INGLEHART, Ronald. Public support for environmental protection: objective problems and subjective values in 43 societies. Political Science \& Politics, v. 28, n. 1, p. 57-72, 1995. https://doi.org/10.1017/S1049096500056080

KASPERSON, Roger E.; RENN, Ortwin; SLOVIC, Paul; BROWN, Halina S.; EMEL, Jacque; GOBLE, Robert; KASPERSON, Jeanne X.; RATICK, Samuel. The social amplification of risk: a conceptual framework. Risk Analysis, v. 8, n. 2, p. 177-187, 1988. 
KITZINGER, Jenny; REILLY, Jacquie. Ascensão e queda de notícias de risco. Coimbra: Edições Minerva Coimbra, 2002.

LIMA, Maria Luísa Pedroso de. Factores sociais na percepção de risco. Revista da Associação Portuguesa de Psicologia, v.12, n. 1, p. 11-28, 1998.

. Percepção de Riscos Ambientais. In: SOCZKA, Luis (Org.). Contextos humanos e psicologia ambiental. Lisboa: Fundação Calouste Gulbenkian, 2005. p.203245.

LOOSE, Eloisa Beling. Riscos climáticos no circuito da notícia local: percepção, comunicação e governança. 2016. 455 f. Tese (Doutorado em Meio Ambiente e Desenvolvimento). Programa de Pós-Graduação em Meio Ambiente e Desenvolvimento, UFPR, Curitiba, 2016.

LOOSE, Eloisa Beling; CAMANA, Ângela. Reflexões sobre o papel do Jornalismo Ambiental diante dos riscos da sociedade contemporânea. Observatorio (OBS*) Journal, v. 9, n. 2, p. 119-132, 2015.

MEDITSCH, Eduardo. Jornalismo e construção social do acontecimento. In: BENETTI, Marcia; FONSENCA, Virginia Pradelina da Silveira (Org.). Jornalismo e acontecimento: mapeamento críticos. Florianópolis: Insular, 2010. p. 19-42.

MCCOMBS, Maxwell. A teoria da agenda: a mídia e a opinião pública. Petrópolis, RJ: Vozes, 2009.

MELO, Itamar. Fábrica de Guaíba preocupa ambientalistas e moradores. Zero Hora. 2015. Disponível em: http://zh.clicrbs.com.br/rs/noticia/2015/07/fabrica-deguaiba-preocupa-ambientalistas-e-moradores-4808922.html. Acesso em: 20 maio 2017.

QUÉRÉ, Louis. Entre facto e sentido: a dualidade do acontecimento. Trajectos. Revista de Comunicação, Cultura e Educação, Lisboa, n. 6, p. 59-75, 2005.

ROTONDARO, Tatiana Gomes. Diálogos entre Bruno Latour e Ulrich Beck: Convergências e divergências. Civitas, v. 12, n. 1, p. 145-160, jan./abr. 2012.

SILVA, Gislene. Para pensar critérios de noticiabilidade. In: SILVA, Gislene; SILVA, Marcos Paulo da; FERNANDES, Mario Luiz (orgs.). Critérios de noticiabilidade: problemas conceituais e aplicações. Florianópolis: Insular, 2014. p.51-69.

SLOVIC, Paul; FINUCANE, Melissa L.; PETERS, Ellen; MACGREGOR, Donald G. Risk as Analysis and Risk as Feelings: Some Thoughts about Affect, Reason, Risk, and Rationality. RiskAnalysis, v. 24, n. 2, p. 311-322, 2004. https://doi.org/10.1111/ j.0272-4332.2004.00433.x

TRAQUINA, Nelson. Jornalismo. Lisboa: Quimera, 2002.

.Teorias do jornalismo: porque as notícias são como são.V.1.2.ed. Florianópolis: 
Insular, 2005.

VEYRET, Yvette. Os riscos: o homem como agressor e vítima do meio ambiente. São Paulo: Contexto, 2007.

WAHLBERG, Anders; SJOBERG, Lennart. Risk perception and the media. Journal of Risk

Research, v. 3, n. 1, p. 31-50, 2000. https://doi.org/10.1080/136698700376699

Recebido em: 9/2/2017

Aceito em: 22/5/2017

Endereço dos autores:

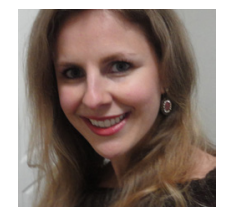

Eloisa Beling Loose <eloisa.beling@gmail.com>

Centro Universitário Internacional (Uninter)

Rua Saldanha Marinho, 131 - Centro

80410-150 - Curitiba (PR) - Brasil

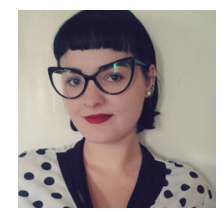

Ângela Camana <angela.camana@hotmail.com>

Programa de Pós-Graduação em Sociologia da Universidade Federal do Rio Grande do Sul (UFRGS)

Av. Bento Gonçalves, 9.500- Sala 103 - Campus do Vale

91509-900 - Porto Alegre (RS) - Brasil

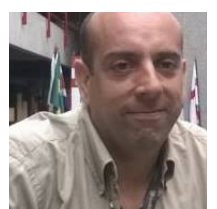

Roberto Villar Belmonte <rvillar21@gmail.com>

Centro Universitário Ritter dos Reis -UniRitter

Rua Orfanotrófio, 555 - Alto Teresópolis

91849-440 - Porto Alegre (RS) - Brasil 